\title{
ESTUDOS SOBRE ALFABETIZAÇÃO E LETRAMENTO NO BRASIL: gêneses, desenvolvimentos e aplicações no ensino ${ }^{1}$
}

Studies on literacy and lettering in Brazil: gêneses, developments and applications in teaching

Francisco Renato Lima ${ }^{2}$

RESUMO: Este estudo traz algumas reflexões acerca dos processos de alfabetização e letramento no Brasil, destacando aspectos de suas gêneses, desenvolvimentos e aplicações no ensino, com foco em permanências e mudanças paradigmáticas em suas práticas, advindas, principalmente, dos estudos da psicogênese da aquisição da língua escrita - o construtivismo -, tratados por Emília Ferreiro e Ana Teberosky, baseadas nas teorias de aprendizagem de Piaget; e também, das pesquisas que tratam de letramento, enquanto prática social de inserção no mundo por meio da leitura e da escrita, que ampliaram e deram novos rumos às concepções teórico-práticas sobre $o$ ato de alfabetizar. Trata-se de uma pesquisa bibliográfica, de caráter qualitativo, no diálogo com autores, como: Barbosa (2013), Cagliari (1998; 2008), Ferreiro; Teberosky (1996; 1999), Kleiman (1995; 2010), Mortatti (2006), Rojo (1998), Soares (2003a; 2003b; 2010; 2011), Tfouni (2010), entre outros. Desde os anos 80 , quando começou a figurar no cenário epistemológico das pesquisas científicas de educação e linguagem, o termo letramento alcunhou novas dimensões e perspectivas aplicadas, de modo que hoje é utilizado para nomear práticas sociais e culturais, que se relacionam com a leitura e a escrita, de forma crítica e participativa, dentre elas, a alfabetização, que representa parte do processo de letramento do sujeito, mediado pela ação da escola.

Palavras-chave: Alfabetização. Teorias da aprendizagem. Mudanças e permanências. Letramento.

ABSTRACT: This study brings some reflections about the processes of literacy and literacy in Brazil, highlighting aspects of their genesis, developments and applications in teaching, focusing on permanences and paradigmatic changes in their practices, mainly coming from studies of the psychogenesis of language acquisition writing constructivism -, treated by Emília Ferreiro and Ana Teberosky, based on Piaget's

1 Este estudo é uma versão atualizada de um texto apresentado na modalidade comunicação oral no Congresso Internacional Linguagem e Interação 3, que aconteceu de 17 a 19 de junho de 2015, na Universidade do Vale do Rio dos Sinos (UNISINOS).

\footnotetext{
${ }^{2}$ Mestre em Letras - Estudos da Linguagem (UFPI). Professor Substituto (Auxiliar Nível - I) da Universidade Federal do Piauí, lotado no Departamento de Métodos e Técnicas de Ensino (DMTE). Coordenador de disciplinas do Centro de Educação Aberta e a Distância (CEAD/UFPI). E-mail: fcorenatolima@hotmail.com
} 
theories of learning; and also of the researches dealing with literacy, as a social practice of insertion in the world through reading and writing, which broadened and gave new directions to theoretical-practical conceptions about the act of literacy. It is a bibliographical research, of qualitative character, in the dialogue with authors, such as: Barbosa (2013), Cagliari (1998; 2008), Ferreiro; Teberosky (1996, 1999), Kleiman (1995, 2010), Mortatti (2006), Rojo (1998), Soares (2003a, 2003b, 2010, 2011), Tfouni (2010), among others. Since the 1980s, when it began to appear in the epistemological scenario of scientific research on education and language, the term literacy has new dimensions and applied perspectives, so today it is used to name social and cultural practices that relate to reading and the writing, in a critical and participative way, among them, literacy, which represents part of the literacy process of the subject, mediated by the school action.

Keywords: Literacy. Theories of learning. Changes and permanencies. Literacy.

\section{CONSIDERAÇÕES INICIAIS}

Os processos e regras de alfabetização se entrelaçam ao próprio surgimento da escrita, como tecnologia de comunicação humana, de modo que alfabetizar está relacionado a capacidade de codificar e decodificar os signos da língua. Ampliando essa noção, pesquisas oriundas do final do século XX, começaram a tratar sobre letramento, enquanto prática social de inserção no mundo por meio da leitura e da escrita. Com isso, reformulou-se as concepções sobre o ato de alfabetizar.

Alfabetização e letramento são tecnologias que caminham juntas, ou melhor, se processam juntas, sendo que o letramento antecede a alfabetização, pois desde que o indivíduo nasce, nas interações sociais que desenvolve com o meio e com seus semelhantes já se torna letrado, condição que será desenvolvida com a interferência da escola, principalmente representada pela ação do educador.

Falar de alfabetização, ora atrelada ou desatrelada ao letramento, recai sobre um discurso corrente nas tendências mais atuais da educação. Muito se trata da alfabetização e do letramento, como fatores isolados e diferentes, mas a ideia é que esses processos sejam unificados e que, nem mesmo nas discussões teóricas, eles ocupem lugares distintos, visto serem processos que se imbricam, se articulam e se fundem na prática pedagógica e nas práticas socioculturais, ou seja, a alfabetização faz parte do processo de letramento, em sentido mais amplo. 
Soares $(2010$, p. 72$)$ reconhece a impropriedade de elaborar um conceito preciso de letramento; a indissociabilidade entre o letramento e a alfabetização e a indissociabilidade entre as dimensões individual e social do letramento; na medida em que "letramento não é pura e simplesmente um conjunto de habilidades individuais; é o conjunto de práticas sociais ligadas à leitura e à escrita em que os indivíduos se envolvem em seu contexto social".

Ler e escrever não são apenas atos mecânicos, mas ações sociais, que se inscrevem na identidade dos sujeitos que as assumem, de forma crítica e autônoma. Integram o quadro de práticas sociais, reconhecendo e valorizando o que o sujeito traz para a escola, aquilo que vivencia em seu cotidiano, e, ao entrar em contato com o conhecimento formal, amplia suas percepções de mundo e modifica suas ações, e, por isso, "cabe à escola mais do que alfabetizar e possibilitar a seus alunos o domínio de um código e, através desse, a convivência com a tradição literária: dela se espera a formação do leitor" (SARAIVA, 2001, p. 23).

Conforme este entendimento, neste estudo apresenta-se algumas reflexões acerca do processo de alfabetização no Brasil, por meio das leituras de Barbosa (2013), Cagliari (1998a; 1998b; 2008), Castanheira (2009), Ferreiro (1996; 2013), Mortatti (2006), Saraiva (2001), Smolka (2008), destacando algumas permanências e mudanças paradigmáticas em suas práticas, advindas, principalmente, dos estudos da psicogênese da aquisição da língua escrita (FERREIRO; TEBEROSKY, 1996; 1999) e dos estudos do letramento (KLEIMAN, 1995; 2010; ROJO, 1998; SOARES, 2003a; 2003b; 2010; 2011; TFOUNI, 2010).

\section{ALFABETIZAÇÃO: REFLETINDO SOBRE ALGUNS CONCEITOS}

O percurso histórico da alfabetização a identifica como o aprendizado dos códigos e ferramentas da escrita, ou seja, o conhecimento do sistema alfabético, que significava apenas a capacidade de codificar, decodificar os signos linguísticos, e reconhecê-los através de sons, o que se denomina fonemas; e reproduzi-los na escrita, o grafema. O educando era considerado alfabetizado, se atendesse a essas demandas básicas, mas, na maioria das vezes, não tinha embasamentos críticos suficientes para entender aquilo que estava lendo ou escrevendo.

Um passeio pela história da alfabetização permite identificar que a manutenção dos métodos de alfabetizar, muitas vezes, tão ultrapassados, opondo- 
se entre métodos analíticos e sintéticos (MAGALHÃES, 2005), confunde-se com a própria história do surgimento dos sistemas de escrita, instituídos pela humanidade. A invenção da escrita e das regras de alfabetização deram-se juntas, de modo que a alfabetização "é a atividade escolar mais antiga da humanidade" (CAGLIARI, 1998a, p. 12). Neste sentido, Mortatti (2006, p. 01) aponta:

\begin{abstract}
Em nosso país, a história da alfabetização tem sua face mais visível na história dos métodos de alfabetização, em torno dos quais, especialmente desde o final do século XIX, vêm-se gerando tensas disputas relacionadas com "antigas" e "novas" explicações para um mesmo problema: a dificuldade de nossas crianças em aprender a ler e a escrever, especialmente na escola pública. Visando a enfrentar esse problema e auxiliar "os novos" a adentrarem no mundo público da cultura letrada, essas disputas em torno dos métodos de alfabetização vêm engendrando uma multiplicidade de tematizações, normatizações e concretizações, caracterizando-se como um importante aspecto dentre os muitos outros envolvidos no complexo movimento histórico de constituição da alfabetização como prática escolar e como objeto de estudo/pesquisa.
\end{abstract}

Ao longo dessas discussões direcionadas às questões educativas, os processos de alfabetização sempre ocuparam lugar de destaque, visto a importância de uma base de aprendizagem sólida, que permita ao indivíduo, o desenvolvimento com eficiência e qualidade, das habilidades cognitivas de leitura e escrita, de maneira a superar os lastimáveis déficits, apontados pelos dados estatísticos do censo escolar que denunciam que o Brasil ainda é um dos países do mundo com mais altos índices de analfabetismo, o que torna justificável a importância do investimento em práticas e ações desenvolvidas pelos educadores, proporcionando aos educandos, as competências leitoras significativas, o letramento.

Identifica-se que o conceito de alfabetização sempre esteve ligado a processos de ensino e aprendizado do sistema alfabético da leitura, ou seja, era apenas ler, decodificar os sinais gráficos da língua, ampliando-os para sinais sonoros; e, na escrita, se refletia na competência de codificar os sons da fala, traduzindo-os em sinais gráficos.

Quanto às formas, os processos metodológicos, o sistema predominante era o tradicional, em que o ensino se constituía de maneira que o professor era uma figura máxima, detentora de um saber pronto, acabado, transmitido para os alunos, que deveriam recebê-lo e respeitar o formato, apenas assimilando e transcrevendo, seguindo as orientações de cartilhas, que se configuravam como elemento de 
acesso aos códigos de alfabetização. Para Cagliari (1998b, p. 66), "as cartilhas dirigem demais a vida do aluno na escola, ele tem que seguir apenas um caminho, por onde todos passam; só pode pensar conforme o método manda e fazer apenas o que está previsto no programa". "Alfabetizar pelas cartilhas (isto é, pelo BaBeBiBoBu) é desastroso" (1998b, p. 67), pois habituam o educando naquele modelo de aprendizagem, no qual ele encontra sempre um conteúdo pronto para ser decodificado. Sobre o tratamento dado a leitura, Mortatti $(2006$, p. 5) destaca que:

Para o ensino da leitura, utilizavam-se, nessa época, métodos de marcha sintética (da "parte" para o "todo"): da soletração (alfabético), partindo do nome das letras; fônico (partindo dos sons correspondentes às letras); e da silabação (emissão de sons), partindo das sílabas. Dever-se-ia, assim, iniciar o ensino da leitura com a apresentação das letras e seus nomes (método da soletração/alfabético), ou de seus sons (método fônico), ou das famílias silábicas (método da silabação), sempre de acordo com certa ordem crescente de dificuldade. Posteriormente, reunidas as letras ou os sons em sílabas, ou conhecidas as famílias silábicas, ensinava-se a ler palavras formadas com essas letras e/ou sons e/ou sílabas e, por fim, ensinavam-se frases isoladas ou agrupadas. Quanto à escrita, esta se restringia à caligrafia e ortografia, e seu ensino, à cópia, ditados e formação de frases, enfatizando-se o desenho correto das letras.

Nessa análise, percebe-se que as cartilhas de alfabetização eram os instrumentos didáticos utilizados pelas escolas de modelo tradicional, para ensinar as crianças aprenderem a ler e escrever. Eram livros esquematizados, que traziam o alfabeto com palavras e ilustrações correspondentes, que o educando decorava as letras e as chamadas "famílias silábicas", e durante o curso das aulas eram chamados a dar conta da leitura, sob forma de sabatina, em cumprimento às tarefas escolares. Sobre isto, Castanheira (2009, p. 24) reflete:

A simples memorização das famílias silábicas não é suficiente para levar o aluno a conhecer diferentes valores sonoros representados pelos grafemas, bem como estruturas silábicas variadas. [...] esse conhecimento/habilidade de reconhecer as diferentes famílias silábicas é parte integrante do processo inicial da aprendizagem da leitura e da escrita, ou seja, a memorização dessas famílias é um dos componentes do processo de alfabetização, mas não é e nem pode ser o único.

Esses métodos de ensino baseavam-se na rigidez do cumprimento de normas, regulados por um sistema de autoritarismo predominante nas relações 
professor $\mathrm{x}$ aluno. Os conteúdos apresentavam-se prontos, concebendo o educando como um ser vazio, sem conhecimentos, que necessitava da interferência do educador para desenvolver-se nos estudos. As atividades utilizadas eram baseadas em práticas superficiais, que não garantiam uma aprendizagem eficaz. Eram pautadas na junção de sílabas simples, memorização de sons, decifração e cópia. Tais métodos e maneiras de conduzir o ensino só permitiam à criança se tornar um espectador passivo ou receptor mecânico do conhecimento, sem uma participação no próprio processo de construção da aprendizagem.

Assim, desconsideravam-se muitas possibilidades, caminhos e vias de acesso ao saber, muitos dos educadores por falta de uma formação e capacitação eficiente, não compreendiam algumas das dificuldades que a criança enfrentavam, antes de entender o verdadeiro sentido da leitura e escrita. Sobre isso, Cagliari (2008, p. 96) observa: "um dos objetivos mais importantes da alfabetização é ensinar a escrever [...], e por isso mesmo requer um tratamento especial".

Atualmente, há um entendimento de que a alfabetização deixou de ser apenas uma absorção do código escrito e passou a ser uma atitude processual, que possibilita a criança o contato com a representação da língua, agregar seus valores históricos e culturais trazidos de suas experiências de mundo e a incorporar no seu dia a dia, como importante instrumento nas relações sociais. É a etapa inicial do processo de escolarização formal do indivíduo. Segundo Ferreiro (1996, p. 24), "o desenvolvimento da alfabetização ocorre, sem dúvida, em um ambiente social. Mas as práticas sociais assim como as informações sociais, não são recebidas passivamente pelas crianças".

De tal modo, não se pode mais entender a alfabetização apenas como a aquisição prática do código da leitura e da escrita, manifestadas pela codificação, que resulta da escrita; e a decodificação, resultante do ato de ler, de forma mecânica e isolada. É preciso rever esse paradigma, "analisar o contexto, de pensar a alfabetização" (SMOLKA, 2008, p. 29), e considerá-la como parte de um processo social sistêmico mais amplo, no qual o sujeito se situa, uma vez que alfabetizar-se consiste em reinventar a linguagem, a experiência, o vivido, e, através da subjetividade, ir além das evidências, contextualizando e refletindo sobre o objeto cognoscível, por meio de três aspectos da linguagem: a fala, a escrita e a leitura.

Esses três elementos funcionam de forma interdependente, necessitam estar em perfeita harmonia para que não haja falha no sistema organizacional da Cadernos Cajuína, v. 4, N. 1, 2019, p.119- 137. 
linguagem e na comunicação. A fala é a primeira das etapas e se manifesta nas situações do dia a dia, fora da escola. É exatamente quando a criança adquire o significado da palavra, entendendo que esta se relaciona com algo concreto que ela observa ou experimenta, ou seja, a criança compreende a relação entre palavra e objeto e os identifica separadamente.

Subjacente a essa etapa, ao entrar na escola, espera-se que a criança já tenha entendimento sobre a compreensão e expressão da palavra falada, e durante a sua fase de alfabetização, esteja apta a alcançar as etapas superiores da linguagem: a leitura e a escrita. Estas atendem a um desenvolvimento diferenciado do ocorrido na fala, pois, apesar de estarem ligados ao anterior, têm suas especificidades e exigem uma proposta diferenciada para a sua apropriação e desenvolvimento com eficiência.

$\mathrm{O}$ acesso à leitura e escrita nos anos iniciais escolares deve basear-se numa perspectiva de alfabetizar e letrar, simultaneamente, através de ferramentas pedagógicas envolventes e enriquecedoras que levem o educando a compreender suas relações com o mundo da linguagem, seja oral ou escrita, ou seja, integrando o processo de construção do saber, sentindo-se protagonista deste, através do contato com a leitura e a escrita. Estas possuem papel fundamental no processo de alfabetização, pois se constituem em fonte de descoberta e prazer, levando o educando ao mundo da informação e da cultura erudita, satisfazendo as suas necessidades de sujeito aprendente e tornando-o crítico em relação às experiências que estabelece com o mundo. Para Saraiva (2001, p. 31), "a alfabetização constróise, assim, através de atividades de uso, contextualizadas e significativas da linguagem oral e escrita, bem como de atividades e análise e reflexão em condição de interlocução, sem a evidência de preconceitos linguísticos".

\section{AS CONTRIBUIÇÕES DOS ESTUDOS DA PSICOGÊNESE DA AQUISIÇÃO DA LÍNGUA ESCRITA: ALGUMAS PERMANÊNCIAS E MUDANÇAS PARADIGMÁTICAS}

No Brasil, a mudança paradigmática que trouxe contribuições significativas no processo de alfabetização, surge nas décadas de 70 e 80 do século $X X$, que configuram-se como momentos de grande importância para a melhoria e ampliação da qualidade das propostas educacionais de alfabetização, que ganha um novo 
conceito a partir das contribuições dos estudos da psicogênese da aquisição da língua escrita, tratados por Emília Ferreiro e Ana Teberosky, que, baseadas nas teorias de aprendizagem, desenvolvidas por Piaget (1896-1980), trazem questões de relevantes para o trabalho docente, no que se refere à tarefa de ensinar a ler e escrever, levando em consideração que um significativo número de crianças fracassa nessas tarefas: os primeiros passos no caminho da alfabetização.

Essa concepção trouxe novos conceitos e referenciais sobre os métodos e formas de alfabetizar, principalmente, sobre as funções sociais do ato de ler. Suas teorias enfatizam que é preciso considerar as diferentes possibilidades que circundam o sujeito que aprende. A ação do educador deve voltar-se para "como se aprende a ler e escrever", e não apenas modos de "como se ensina". Essa concepção ficou conhecida no meio educativo como Construtivismo ${ }^{3}$.

Ferreiro; Teberosky (1999) apontam que as crianças passam por diferentes hipóteses - espontâneas e provisórias -, até elaborar conhecimentos sobre a leitura e escrita e se apropriar de toda a complexidade da língua. Tais hipóteses são baseadas em conhecimentos prévios, assimilações e generalizações e dependem das interações com os pares e com os materiais escritos que circulam socialmente.

Os anos 80, ainda significaram um marco na ampliação dos conceitos, que posteriormente mudaram os rumos da alfabetização. Os estudos das autoras, contribuíram na medida em que, a proposta aponta que o aprendizado do sistema escrito não se reduz apenas ao domínio da leitura e escrita, representados pela correspondência entre grafemas e fonemas. Isso limita apenas a decodificação e codificação dos signos linguísticos. Em contrapartida, deve-se considerar a dinâmica social do processo, por meio do qual, a criança, a partir dos primeiros contatos com a escrita, constrói e reconstrói hipóteses sobre a natureza e funcionamento da língua. Esta, por sua vez, entendida como um sistema de representação organizado e que, portanto, necessita de um olhar cuidadoso e particular, estabelecendo uma relação direta com o objeto conhecível.

Em análise sobre a importância das teorias e métodos decorrentes desse modo de organização teórico-conceitual do processo de alfabetização, Soares (2011, p. 89) reflete:

${ }^{3}$ Concepção Piagetiana, que considera que o sujeito é o protagonista na aquisição do conhecimento. A intervenção do indivíduo na realidade que o envolve constitui o fator preponderante da acepção do autor sobre o "ato de conhecer", explicitado reiteradamente em suas obras (COLL, 2000). 
A concepção psicogenética, deslocando o eixo de compreensão e interpretação do processo pelo qual a criança aprende a ler e a escrever, trouxe uma severa crítica à importância que vinha sendo atribuída ao método de alfabetização. [...] [Ela] alterou profundamente a concepção do processo de aquisição da língua escrita, em aspectos fundamentais: a criança, de aprendiz dependente de estímulos externos para produzir respostas que, reforçadas, conduziriam à aquisição da língua escrita - concepção básica dos métodos tradicionais de alfabetização - passa a sujeito ativo capaz de construir o conhecimento da língua escrita, interagindo com esse objeto do conhecimento [...]. (Grifos no Original)

Em 1990, ocorreu na Tailândia, a Conferência Mundial sobre Educação para Todos, a qual, trouxe uma compreensão sobre alfabetização, que passa a ser "entendida como instrumento eficaz para a aprendizagem, para o acesso e para a elaboração da informação, para criação de novos conhecimentos e para a participação na própria cultura e na cultura mundial nascente" (CASTANHEIRA, 2009, p. 14).

A partir dessa definição, passou-se a entender que a aquisição dos processos cognitivos de leitura e escrita devem acontecer com sentido e eficácia, tornando o indivíduo alfabetizado, dentro de uma perspectiva de letramento. Isso resulta de uma correlação de habilidades e comportamentos, que se saem do simples ato de decodificar sílabas ou palavras e alcança a leitura destas, com significado e significância social.

A alfabetização constitui-se, portanto, como fase de grande relevância no processo de formação do indivíduo, é onde a criança assimila formalmente os conhecimentos sobre o sistema alfabético da escrita, com domínio do código linguístico e das habilidades necessárias para desempenhar uma importante função social: ler e escrever. Para que essa etapa seja alcançada com êxito é necessário o desenvolvimento de competências (atitudes, habilidades, conhecimentos) de uso efetivo e significativo da língua em práticas sociais que envolvam a escrita, como interpretar e produzir textos de diferentes tipos e gêneros, o que se chama de letramento, conceito fundamental neste estudo, e sobre o qual trata-se a seguir. 
4. PERSPECTIVAS DE LETRAMENTO: AMPLIANDO OS SENTIDOS DA ALFABETIZAÇÃO E REPENSANDO O PAPEL DO PROFESSOR NO DESENVOLVIMENTO DA LEITURA E DA ESCRITA

O surgimento do termo letramento está diretamente relacionado à alfabetização, por isso, foi necessária a ampliação dos estudos sobre as relações de semelhança e distinção entre esses processos, muitas vezes, conflituosos de compreensão. O termo é corrente nos ambientes escolares, porém, a questão semântica ainda gera dúvidas, o que resulta numa dicotomia entre teoria e prática, conforme evidenciam as experiências advindas dos cursos de formação docente, e da prática docente, em que os educadores apresentam constantes dúvidas sobre alfabetizar e letrar (CASTANHEIRA, 2009).

O entendimento de que a alfabetização deixou de ser apenas uma absorção do código escrito e passou a ser uma atitude processual, que possibilita ao educando, ter contato com a representação da língua, agregar seus valores históricos e culturais (TFOUNI, 2010) trazidos de suas experiências de mundo e incorporar as relações sociais cotidianas, tem sido uma das principais questões que permeia o discurso de estudiosos da educação e da linguagem.

Razões como essa, fazem com que até mesmo, trazer conceitos e definições do que seja letramento apresente-se como uma tarefa muito complexa, visto que é difícil estabelecer uma formulação sem correr o risco de deixar alguma lacuna ou restrição quanto ao entendimento. Para defini-lo é recomendável que comece por colocá-lo por níveis e, assim, estabelecer critérios de condição de letrado. Não se pode falar em um conceito único, pois seu sentido não é unânime, mesmo entre os principais estudiosos do assunto.

[...] alfabetização e letramento são conceitos frequentemente confundidos ou sobrepostos, é importante distingui-los, ao mesmo tempo que é importante também aproximá-los: a distinção se faz necessária porque a introdução, no campo da educação, do conceito de letramento tem ameaçado perigosamente a especificidade do processo de alfabetização; por outro lado, a aproximação é necessária porque não só o processo de alfabetização, embora distinto e específico, altera-se e reconfigura-se no quadro do conceito de letramento, como também este é dependente daquele. (SOARES, 2003a, p. 90) 
Letramento e alfabetização são, portanto, processos que devem ser indissociáveis na aprendizagem do educando. $O$ primeiro inicia-se logo que o indivíduo nasce, nas primeiras relações que estabelece socialmente, nas relações interpessoais e com os objetos informativos e da escrita e que o rodeia; e o segundo é introduzido no repertório cultural da criança, por meio da entrada na escola.

O letramento constitui-se da construção social da língua falada e escrita, através da elaboração de formas e contextos diferenciados. "Enquanto a alfabetização se ocupa da aquisição da escrita por um indivíduo, ou grupo de indivíduos, o letramento focaliza os aspectos sócio-históricos da aquisição de um sistema escrito por uma sociedade" (TFOUNI, 2010, p. 22). A condição de letrado pressupõe o entendimento mais amplo que o processo da alfabetização, tomando-a como fenômeno isolado. Soares (2003b, p. 92) define:

Ao exercício efetivo e competente da tecnologia da escrita denominase letramento que implica habilidades várias, tais como: capacidade de ler ou escrever para atingir diferentes objetivos - para informar-se, para interagir com outros, para imergir no imaginário, no estético, para ampliar conhecimentos, para seduzir ou induzir, para divertir-se, para orientar-se, para apoio à memória, para catarse...; habilidades de interpretar e produzir diferentes tipos e gêneros de textos, habilidades de orientar-se pelos protocolos de leitura que marcam o texto ou de lançar mão desses protocolos, ao escrever, atitudes de inserção efetiva no mundo da escrita, tendo interesse e prazer em ler e escrever, sabendo utilizar a escrita para encontrar para ou fornecer informações e conhecimentos, escrevendo ou lendo de forma diferenciada, segundo as circunstâncias, os objetivos, o interlocutor.

Esse entendimento traz a dimensão da importância do letramento nos modelos educativos da atualidade, para que o ensino se firme como elemento essencial à formação humana e "[...] para que as pessoas que vivem numa cultura que conhece as letras não continuem roubadas de um direito - o de somar à 'leitura' que já fazem do mundo a leitura da palavra, que ainda não fazem" (FREIRE apud BARRETO, 1998, p. 77).

Nesse sentido, letramento é um estado ou condição humana adquirida pelas relações sociais formais ou informais do meio em que o indivíduo vive, e através da leitura, passa a interpretar e transformar o mundo, de maneira a inserir-se como sujeito autêntico de sua história e da sua sociedade. A pessoa letrada é um ser pensante sobre o mundo, que organiza seus espaços de convivência social e 
política, por meio da interlocução com a palavra ${ }^{4}$ e com os sentidos e significados que ela transmite.

Promover uma alfabetização que leve ao letramento é criar dentro da relação de ensino e aprendizagem, na sala de aula, propostas de ensino dinâmicas, inovadoras, que levem a situações de interpretação e interação com a língua materna. Sobre isso, Kleiman (1995, p. 19; 2010, p. 379), traz algumas considerações acerca das relações entre escolarização, alfabetização e letramento:

As práticas específicas da escola, que forneciam o parâmetro de prática social segundo a qual o letramento era definido, e segundo a qual os sujeitos eram classificados ao longo da dicotomia alfabetizado ou não-alfabetizado, passam a ser, em função dessa definição, apenas um tipo de prática - de fato, dominante - que desenvolve alguns tipos de habilidades mas não outros, e que determina uma forma de utilizar o conhecimento sobre a escrita.

A alfabetização é uma prática de letramento que pode envolver diferentes estratégias (reconhecimento global da palavra, reconhecimento de sílabas, leitura em voz alta, leitura silenciosa), diversos gêneros (cartilhas, exercícios, imagens, notícias, relatos, contos, verbetes, famílias de palavras), diferentes tecnologias (lápis, caneta, papel, quadro negro, giz, lousa branca, pincel atômico, livro, tela e teclado).

Frente às tantas exigências do meio social, com significativas implicações no contexto educacional, é necessário que os sujeitos da aprendizagem adquiram um conjunto de habilidades diversas, para que possam ter uma atuação coerente e participativa nas questões de ordem sociais e políticas, de maneira a construir uma sociedade mais democrática e justa, na qual possam exercer seus direitos e deveres e sejam vias de comunicação humana, elevando assim, as condições de desenvolvimento social e diminuição dos alarmantes casos de analfabetismo.

Rojo (1998) compreende o letramento como prática social, explicitando as funções e impactos sociais da escrita na vida do sujeito, desde as relações familiares de ordem primária às relações secundárias estabelecidas na escola:

${ }^{4}$ Do zelo com os significados e significação da palavra, enquanto instrumento crítico de participação no mundo, como se propõe neste texto, Bakhtin; Volochinov (2004, p. 41), apontam que: "[...] tecidas a partir de uma multidão de fios ideológicos e servem de trama a todas as relações sociais, em todos os domínios. É portanto claro que a palavra será sempre o indicador mais sensível de todas as transformações sociais, mesmo daquelas que apenas despontam, que ainda não tomaram forma, que ainda não abriram caminho para sistemas ideológicos estruturados e bem formados". 
[...] o desenvolvimento da linguagem escrita ou do processo de letramento da criança é dependente, por um lado, do grau de letramento da instituição familiar a que pertence - isto é, da maior ou menor presença, em seu cotidiano, de práticas de leitura e de escrita - e, por outro, como ressalta Lemos (1988:11), dos ... diferentes modos de participação da criança nas práticas discursivas orais em que estas atividades ganham sentido. [...] é o modo de participação da criança, ainda na oralidade, nestas práticas de leitura/escritura, dependentes do grau de letramento familiar (e, acrescentaríamos, da instituição escolar e/ou pré-escolar em que a criança está inserida), que the permite construir uma relação com a escrita enquanto prática discursiva e enquanto objeto. (ROJO, 1998, p. 123) (Grifos do autor)

Desse modo, realça-se a relevância dos processos de leitura mediatizados pela escola, como via de acesso ao letramento, de modo que "as pessoas procuram descobrir, cultivar e empregar seus supostos recursos interiores e transformar sua subjetividade" (RUDIGER, 1996, p. 11). Ler não é apenas uma decodificação dos signos linguísticos, mas o estabelecimento de uma ponte de sentidos e significados entre o simbólico e os fatos reais. A compreensão do objeto lido é alcançada pelo desejo de decifrar e interpretar o sentido das coisas e dos fenômenos sociais e de ampliar as percepções de mundo, de forma heterogênea, por isso, a leitura deve ser a etapa inicial para o desenvolvimento da escrita e para a construção de sentidos. Soares (2010, p. 18) aponta que "o letramento é o resultado da ação de ensinar ou de aprender a ler e escrever: o estado ou a condição que adquire um grupo social ou um indivíduo como consequência de ter-se apropriado da escrita".

Os conceitos postulados sobre letramento, sempre o associam ao domínio das competências de ler e escrever transmitidas pela escola, mas é urgente o pensar em uma definição mais ampla, que respeite a diversidade cultural de cada indivíduo, considerando que o sujeito nasce e cresce interagindo com veículos de informação e comunicação (placas, jornais, rádios, televisão, entre outros) presentes no meio em que vive e que já o tornam, de certa forma, letrados. Desse modo, compreende-se o letramento como um percurso de inserção e participação do indivíduo no mundo da escrita, que acontece em diferentes instâncias sociais em que o sujeito vive, desde o seu nascimento e se estende durante toda a vida, envolvendo-se com as práticas de leitura e escrita formais ou não formais.

Quanto à leitura, esta é um processo pelo qual se compreende a linguagem escrita; e a partir disso, intervém, tanto o texto (sua forma e conteúdo) quanto o leitor (suas expectativas e conhecimentos prévios) e, portanto, para ler, é necessário, ao 
mesmo tempo, manejar com destreza as habilidades de decodificação e distinguir, no texto, os objetivos, as ideias, as experiências prévias e mesmo a motivação ${ }^{5}$; ler é um processo de (re) construção dos próprios sentidos do texto (SOLÉ, 1998).

É fundamental o investimento em práticas significativas de leitura, que levem o educando a interagir com diversos gêneros textuais, pois a leitura apresenta-se como uma ferramenta facilitadora do processo de formação do sujeito, nos aspectos sociais, cognitivo e culturais, visto que é através dela que se chega a uma situação concreta de aprendizagem. Para Hoffmann (2009, p. 02), "através da leitura todos se tornam iguais, com as mesmas oportunidades. A leitura, além de tornar o homem mais livre, possibilita que ele vá a muitos lugares que sem a leitura jamais iria".

Por isso, é de fundamental importância que, desde o início, a alfabetização se dê num contexto de interação pela [leitura e] escrita. Por razões idênticas, deveria ser banido da prática alfabetizadora todo e qualquer discurso (texto, frase, palavra, "exercício") que não esteja relacionado com a vida real ou o imaginário das crianças, ou em outras palavras, que não esteja por elas carregado de sentido (OLIVEIRA, 1998, p. 70-71).

A leitura é de fundamental importância no processo de ensino e aprendizagem da criança. Tanto aquela apresentada pela família, quanto pela escola, têm um caráter formativo e dialógico. Nesse entremeio, tanto as obras de ficção (da literatura), como os estudos científicos, culturais e históricos transmitidos pelas disciplinas que compõem o currículo das escolas, devem estar vinculados às práticas intencionais de leitura.

Um processo eficiente de alfabetização deve propiciar ao educando o entendimento de que aprender a ler e escrever requer não apenas o conhecimento de uma variedade de conteúdos, mas o domínio e interação com estes, de maneira ampla e intencional, transformando as informações abstratas, encontradas em diferentes veículos informativos, em conhecimentos próprios, construídos pela análise, síntese e reflexão de ideias. Para Cagliari (1998b, p. 66), "um método de alfabetização que leve em conta o processo de aprendizagem deve deixar um espaço para que o aluno exponha suas ideias a respeito do que aprende".

\footnotetext{
${ }^{5}$ Acerca de leitura e motivação, Yunes (1984, p. 53) aponta que "o estímulo sistemático à leitura deveria ser meta prioritária em países em via de desenvolvimento. Constata-se no Brasil que o hábito de ler não representa uma tradição e, por isso, a motivação através de técnicas específicas deve ser encarada como um campo de estudo e pesquisa de novas modalidades que visem à aproximação do livro com o leitor".
} 
É urgente o investimento em atividades de leitura e escrita sob diversos gêneros e situações no contexto escolar, levando os educandos a refletir sobre as possibilidades do mundo da fantasia, do imaginário e do real. A escola deve promover encontros e relações diversas entre o educando e a leitura, através de desenvolvimento de projetos pedagógicos, rodas e oficinas de leitura, trazendo uma nova concepção de ensino e aprendizagem, refletida na formação de jovens leitores. Os educandos precisam ser levados a desenvolverem estratégias de leitura, como antecipação, checagem de hipóteses, seleção, inferência, comparação e verificação (SOLÉ, 1998), entre outros modos de como se apropriar da mensagem do texto, adotando um posicionamento crítico e ampliando o vocabulário e o raciocínio lógico.

É importante um repensar sobre essa situação, pois o que se percebe na prática escolar é que, muitas vezes, o insucesso na fase de alfabetização se deve à falta de investimento em práticas efetivas de leitura, o que traz a urgência em refletir sobre as práticas docentes, com vistas à mudanças que possam conferir um novo sentido aos modelos de ensino, uma vez que, "o que chamamos hoje de processo de alfabetização comporta, então, a aprendizagem coletiva e simultânea dos rudimentos da leitura e da escrita" (BARBOSA, 2013, p. 16).

Assim, cabe à escola, como instituição por excelência em sistematização e organização do saber, oportunizar ao educando situações de acesso à leitura e escrita de maneira formal e crítica, ampliando seus referenciais de cidadania, dignidade e criticidade em leitura de mundo.

$\mathrm{Na}$ heterogeneidade de situações de aprendizagem e ensino da língua, o profissional educador deve procurar estratégias que envolvam as possibilidades de aprendizagem de cada indivíduo, intervindo não apenas com métodos prontos, mas proporcionando situações que atendam todas as crianças, e, nesse percurso, deve buscar conhecer seu aluno para que saiba como cada um aprende e compreende a leitura e a escrita. Sobre isso, Saraiva (2001, p. 33), complementa:

O grande desafio proposto ao professor é alfabetizar crianças tendo o texto como unidade básica e ensinar a ler e escrever a partir da reflexão sobre o processo envolvido na alfabetização. A autonomia na leitura desenvolve-se com o aumento da experiência, na medida em que ocorre a ampliação de conhecimentos que servem de apoio à identificação das palavras, de frases e de modalidades de texto. 
O papel do educador é de mediador e estimulador de condições que levem a aprendizagem, direcionando o educando ao senso crítico, tornando-o um ser investigativo e questionador, frente à realidade que se insere. Ele é o responsável por orientá-lo às funções sociais da leitura e da escrita, e, para isso, deve lançar mão de recursos variados, como diferentes gêneros textuais, vídeos, revistas, livros infantis, entre outros recursos que aproximem educando e conhecimento. "Encarando o processo de aprendizagem como fruto de sua interação com os alunos, tendo cada parte um papel, age naturalmente, sem usar chavões, como se essa atitude fluísse de seu papel profissional", declara Kramer (2010, p. 54), a respeito do compromisso que o professor deve assumir com a aprendizagem.

Cabe, portanto, levar a maior variedade e diversidade textual possível para o espaço da sala de aula, permitindo assim, que o educando interaja com diferentes mídias de leitura e formação letrada e educativa, promovendo, ao mesmo tempo, a alfabetização e o letramento, através de situações articuladas com a realidade, permitindo o desenvolvimento da aprendizagem, de forma criativa e reflexiva sobre a língua como prática social, na qual os sujeitos se constroem na e sobre ela.

\section{CONSIDERAÇÕES FINAIS}

A análise dos aspectos teóricos da alfabetização, com proposta de letramento, baseadas nos fundamentos da pedagogia crítica e nas concepções contemporâneas dos processos de ensino e aprendizagem, destacam a importância do investimento em ações, reflexões, discussões e, principalmente, revisão e reformulação de práticas tradicionais de alfabetização. Esta refere-se às condições de ler e escrever, através do uso dos recursos da língua escrita; enquanto o letramento amplia esse processo, ao exigir do indivíduo a capacidade de ler e escrever, inferindo sentido e reformulando o objeto da leitura e da escrita.

A parceria alfabetizar letrando precisa ser estreitada e construída diariamente nas práticas pedagógicas, com o objetivo de promover um diálogo entre o mundo abstrato da leitura e o mundo real do indivíduo em processo de aprendizagem. Letrar vai além do alfabetizar e exige do educando a capacidade de encontrar sentido naquilo que lê e escreve.

As reflexões apresentadas neste estudo ressaltam alguns aspectos relacionados à questão da alfabetização no Brasil, destacando algumas 
permanências e mudanças paradigmáticas em suas práticas, advindas principalmente, dos estudos da psicogênese da aquisição da língua escrita, de Emília Ferreiro e Ana Teberosky; acrescidos dos estudos do letramento, enquanto prática social de inserção no mundo por meio da leitura e da escrita, que ampliaram e deram novos rumos às concepções teóricas-práticas sobre o ato de alfabetizar.

O processo de alfabetização deve estar integrado ao letramento, como ação social que extrapola os limites da escola, sendo apenas reforçado por ela, uma vez que ele se inicia nas atividades de convívio familiar, desde que o indivíduo nasce. Ao entrar na escola, ele ampliará seu nível de letramento, na medida em que se apropriará dos mecanismos da língua materna, sendo capaz de exprimir-se com mais fluência e capacidade de articulação linguística, pelo domínio da fala e escrita e agindo com senso crítico, nas diversas situações a que for submetido socialmente.

Esses apontamentos teóricos apontam enfim, que o aprendizado do sistema escrito não se reduz apenas ao domínio da leitura e escrita, representado pela correspondência entre grafemas e fonemas, mas é preciso considerar as diferentes possibilidades que circundam o sujeito que aprende e preocupar-se em "como se aprende a ler e escrever", e não apenas modos de "como se ensina". Daí, o investimento em práticas pedagógicas voltadas para o desenvolvimento dessas habilidades, por meio de diferentes agências e mídias de acesso à leitura, de forma que promova o educando nas habilidades de alfabetizado em uma perspectiva de letramento, respondendo a contento as demandas sociais da contemporaneidade.

\section{REFERÊNCIAS}

BAKHTIN, Mikhail (VOLOCHINOV, Valentin Nikolaevich). Marxismo e filosofia da linguagem. 11. ed. São Paulo: Hucitec, 2004.

BARBOSA, José Juvêncio. Alfabetização e leitura. 3. ed. São Paulo: Cortez, 2013.

BARRETO, Vera. Paulo Freire para educadores. São Paulo: Arte \& Ciência, 1998.

CAGLIARI, Luiz Carlos. Alfabetizando sem o bá-bé-bi-bó-bu. São Paulo: Scipione, 1998a.

A respeito de alguns fatos do ensino e da aprendizagem da leitura e da escrita pelas crianças na alfabetização. In: ROJO, Roxane (Org.). Alfabetização e 
letramento: perspectivas linguísticas. Campinas: Mercado das Letras, 1998b. p. 61 86.

Alfabetização \& linguística. 10. ed. São Paulo: Scipione, 2008.

CASTANHEIRA, Maria Lúcia; MACIEL; Francisca Izabel Pereira; MARTINS; Raquel Márcia Fontes. Alfabetização e letramento na sala de aula. 2. ed. Belo Horizonte: Autêntica, 2009.

COLL, C. A teoria genética da educação. In: Psicologia do ensino. Porto Alegre: Artmed, 2000.

FERREIRO, Emília. Alfabetização em processo. São Paulo: Cortez, 1996.

. O ingresso na escrita e nas culturas do escrito: seleção de textos de pesquisa. Tradução Rosana Malerba. São Paulo: Cortez, 2013. 1999.

; TEBEROSKY, Ana. Psicogênese da língua escrita. Porto Alegre: Artmed,

KLEIMAN, Ângela B. Modelos de letramento e as práticas de alfabetização na escola. In: KLEIMAN, Ângela B. (Org.). Os significados do letramento: uma nova perspectiva sobre a prática social da escrita. Campinas: Mercado das Letras, 1995. p. $15-61$.

. Trajetórias de acesso ao mundo da escrita: relevância das práticas não escolares de letramento para o letramento escolar. Perspectiva, Florianópolis, v. 28, n. 2, 375-400, jul./dez. 2010. Disponível em: < http://www.perspectiva.ufsc.br > . Acesso em: 12 mar. 2017.

KRAMER, Sonia. Alfabetização, leitura e escrita: formação de professores em foco. São Paulo: Ática, 2010.

HOFFMANN, Jussara. Texto de Hoffmann relacionado à Leitura. 2009. Disponível em: < http://doidoeusodeperto.blogspot.com/2009/05/texto-de-hoffmann-relacionadoleitura.html >. Acesso em: 04 nov. 2017.

MAGALHÃES, N. Conhecer a história dos métodos de ensino para alfabetizar no presente. Letra A - O jornal do Alfabetizador. Centro de Alfabetização, Leitura e Escrita. Faculdade de Educação/UFMG, Belo Horizonte, ago/set., 2005, p. 6-9.

MORTATTI, Maria Rosário Longo. História dos métodos de alfabetização no Brasil. Conferência proferida durante o Seminário "Alfabetização e letramento em debate", promovido pelo Departamento de Políticas de Educação Infantil e Ensino Fundamental da Secretaria de Educação Básica do Ministério da Educação, realizado em Brasília, em 27/04/2006. Disponível em: < http://portal.mec.gov.br/seb/arquivos/pdf/Ensfund/alf mortattihisttextalfbbr.pdf $>$. Acesso em: 12 mai. 2017. 
OLIVEIRA, Anne Marie M. A formação de professores alfabetizadores: lições da prática. In: GARCIA, Regina L. Alfabetização dos alunos das classes populares. São Paulo: Cortez, 1998.

ROJO, Roxane (Org.). Alfabetização e letramento: perspectivas linguísticas. Campinas: Mercado das Letras, 1998.

RUDIGER, F. R. Literatura de autoajuda e individualismo: contribuições ao estudo da subjetividade na cultura de massa contemporânea. Porto Alegre: Ed. UFRGS, 1996.

SARAIVA, Juracy Assmann (Org.). Literatura e alfabetização: do plano do choro ao plano da ação. Porto Alegre: Artmed, 2001.

SOARES, Magda. Letramento: um tema em três gêneros. 4. ed. Belo Horizonte: Autentica, 2010.

SOARES, Magda. Alfabetização e letramento. São Paulo: Contexto, 2003a.

Alfabetização e letramento. 6. ed. São Paulo: Contexto, 2011. . Letramento e escolarização. In: RIBEIRO, Vera Masagão (Org.).

Letramento no Brasil: reflexões a partir do INAF 2001. São Paulo: Global, 2003b. p.89-115.

SMOLKA, Ana Luiza Bustamante. A criança na fase inicial da escrita: a alfabetização como processo discursivo. 12. ed. São Paulo: Cortez, 2008.

SOLÉ, I. Estratégias de leitura. 6. ed. Porto Alegre: Artmed, 1998.

TFOUNI, Leda Verdiani. Letramento e alfabetização. São Paulo: Cortez, 2010.

YUNES, E. A leitura e a formação do leitor: questões culturais e pedagógicas. Rio de Janeiro: Antares, 1984. 